\title{
Efficacy of Cognitive-Behavioral Stress Management Training on Symptoms Severity and Emotional Well-being of Patients with Irritable Bowel Syndrome
}

\author{
Soleymani P.* MSc, Abolghasemi A. ${ }^{1}$ PhD, Vakilee Abasaliloo S. ${ }^{2}$ MSc, \\ Rahimi A. ${ }^{3}$ PhD, Bayramzadeh N. ${ }^{4}$ MSC

\begin{abstract}
*Psychology Department, Science Faculty, Ardabil Branch, Islamic Azad University, Ardabil, Iran 1Psychology Department, Human Science \& Literature Faculty, University of Guilan, Rasht, Iran ${ }^{2}$ Psychology Department, Humanity Faculty, Tabriz University, Tabriz, Iran 3Internal Department, Medical Faculty, Tehran University of Medical Science, Tehran, Iran
\end{abstract} \\ ${ }^{4}$ Psychology Department, Science Faculty, Ardabil Branch, Islamic Azad University, Ardabil, Iran
}

\begin{abstract}
Aims: One of the most prevalent gastrointestinal functional disorders is the irritable bowel syndrome (IBS). Different medical and psychological treatments are conducted to control the symptoms of the disease. The aim of this study was to determine the effectiveness of the cognitive-behavioral stress management training on the severity of the symptoms and emotional welfare of patients with IBS.

Materials \& Methods: In the controlled pretest-posttest clinical trial study, 30 patients with IBS were studied in Ardabil in 2012. The subjects, selected via available sampling method, were randomly divided into two groups including experimental $(n=15)$ and control $(n=15)$ groups. Data was collected using the IBS severity questionnaire, the characteristic positive and negative affection scale, and the life satisfaction scale. Ten 90-minute group cognitive-behavioral stress management treatment sessions were conducted in experimental group. The subjects were assessed at both pretest and posttest steps. Data was analyzed by SPSS 20 software using multivariate covariance analysis test.

Findings: The mean scores of positive affection, negative affection, life satisfaction, and IBS symptom severity of experimental and control groups were significantly different at the posttest step ( $\mathrm{p}<0.001) .51 \%, 55 \%, 89 \%$, and $57 \%$ of positive affection component, negative affection component, life satisfaction, and IBS symptom severity variances could be determined by the cognitive-behavioral stress management training, respectively.

Conclusion: The cognitive-emotional stress management treatment can reduce the severity of the symptoms, while it can increase the emotional welfare, in the patients with IBS.
\end{abstract}

\section{Keywords}

Stress (Psychological)[https://www.ncbi.nlm.nih.gov/mesh/68013315];

Signs and Symptoms [https://www.ncbi.nlm.nih.gov/mesh/68012816];

Emotions [https://www.ncbi.nlm.nih.gov/mesh/68004644];

Irritable Bowel Syndrome [https://www.ncbi.nlm.nih.gov/mesh/68043183]

\footnotetext{
${ }^{*}$ Corresponding Author

Tel: +98 (45) 33256247

Fax: $+98(45) 33337677$

Address: Andishe-ye-no Consulting and Psychological Office, Alghadir Building, Sarcheshmeh Square, Ardabil, Iran. Postal Code: 5614668149

p62.soleymani@gmail.com

Received: December 18, 2015 


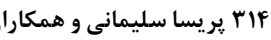

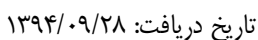

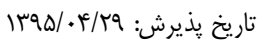

"نويسنده مسئول: p62.soleymani@gmail.com

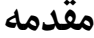

سندروم روده تحريكيذير (IBS)، اختلال كاركردى مزمن دستگاه

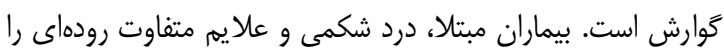

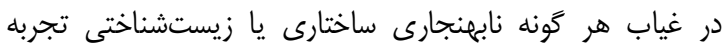

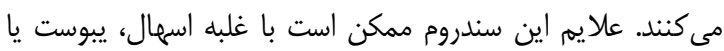
تركيبى از هر دو همراه باشد[1]. اين اختلال در همه كروههاى

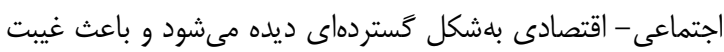
از كار، اختلال در روابط بينفردى، يرهيز از مقاربت جنسى و حتى إنى

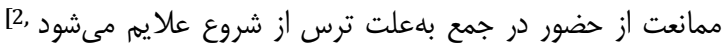

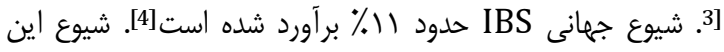

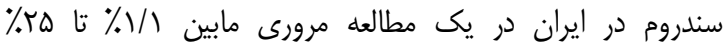

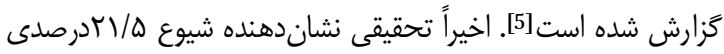
IBS

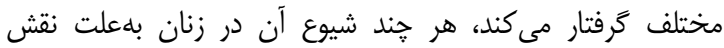

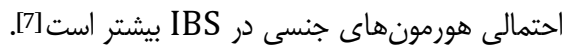
سببشناسى IBS بلهور كامل شناختهشده نيست. عوامل متفاوت از جمله كاهش سلولهاى غدد درونريز سيستم گوارش، افزايش حساسيت احشايى، التهاب موضعى، فلور غيرطبيعى روده و عوامل روانشناختى را در شكل حيرى آن دخيل مىدانند [12-8]. سندروم

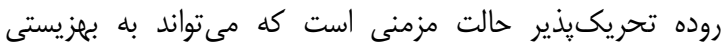

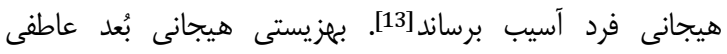
بهزيستى ذهنى است و شامل مولفههاى وجود عواطف مثبت، فقدان عواطف منفى و رضايتمندى از زندگى است [14].

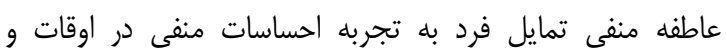
موقعيتهاى مختلف است[15]. بين عاطفه منفى و شدت علايم

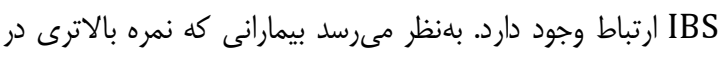

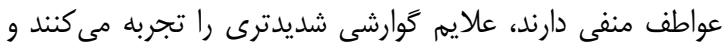
در مقابل، تشديد علايم نيز سطح تجربه عواطف منفى رارئ رابل بالا

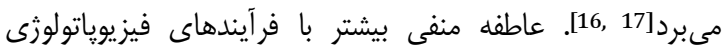

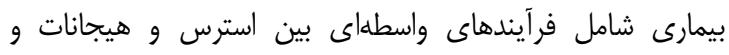

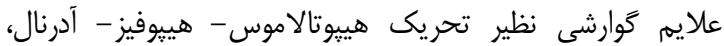

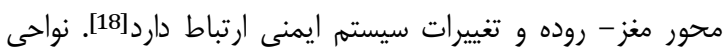

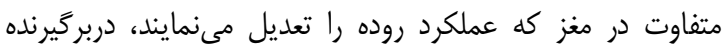

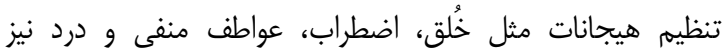

هستند[19].

در مقابل عاطفه مثبت نشان مىدهد كه يك شخص تا خه ميزان

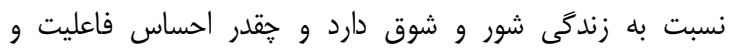
هوشيارى مى كند. عاطفه مثبت بالا بر انرزى زياد، تمركز كامل و ولتور

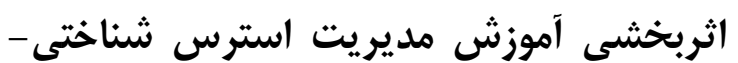
رفتارى بر شدت علايم و برزيستى هيجانى بيمار ان مبتلا به سندرم روده تحريكيذيذ

يريسا سليمانى" MSc

كروه روانشناسى، دانشكده علوم، واحد اردبيل، دانشگاه آزاد اسلامى، اردبيل،

ايران

عباس ابوالقاسمى PhD

كروه روانشناسى، دانشكده علوم انسانى و ادبيات، دانشخاه كَيلان، رشت، ايران

MSc سجاد وكيلى عباسعليلو

كروه روان شناسى، دانشكده انسانى، دانشعاه تبريز، ايران

عارف رحيمى PhD

كروه داخلى، دانشكده يزشكى، دانشكاه علوم يزشكى تهران، ايران

نسرين بايرامزاده

كروه روان شناسى، دانشكده علوم، واحد اردبيل، دانشكاه آزاد اسلامى، اردبيل،

ايران

جكيده

اهداف: سندروم روده تحريكيذير (IBS) از شايعترين اختلالات

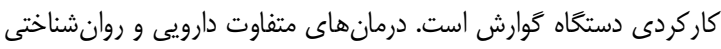

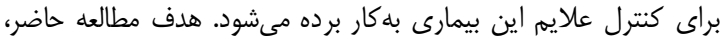

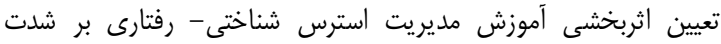

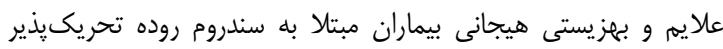

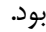

مواد و روشها: در اين كارآزمايى بالينى با طرح بيشرآزمون و

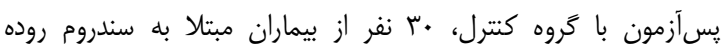

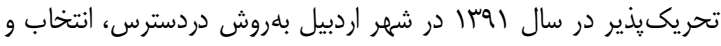

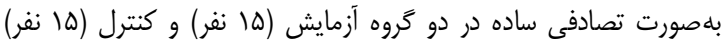

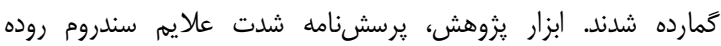

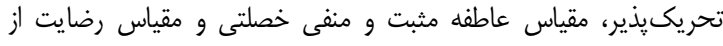

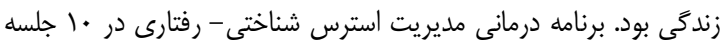

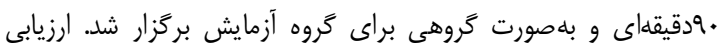

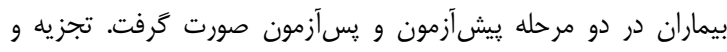
تحليل دادهها بهكمى نرمافزار SPSS 20 و با با استفاده از آزمون تحليليل

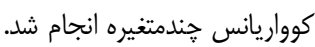

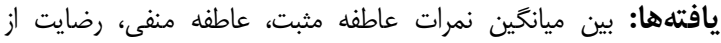

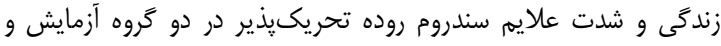

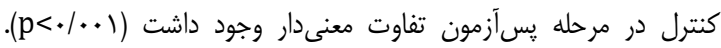

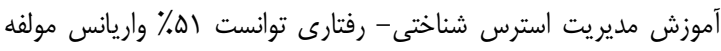

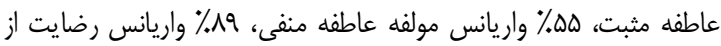

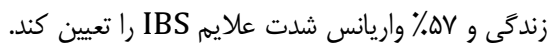
نتيجلَّيرى: درمان مديريت استرس شناختى - رفتارى مى متواند در

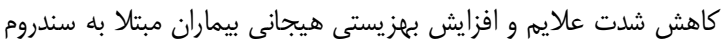

روده تحريكيذير موثر باشد. كليدوازهها: استرس (روانشناختى)، علايم، هيجان، سندروم روده تحريكيذيذير 


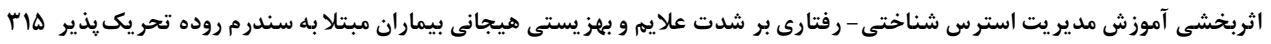

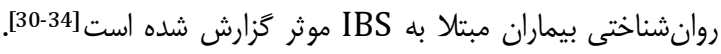

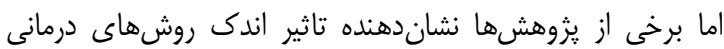
روانشناختى بودهاند[35]. با توجه به نتايج متناقض تحقيقات يادشده و نقش نقد استرس در اين سندروم، هدف از يزوهش حاضر، بررسى اثربخشى آموزش مديريت

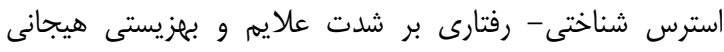

بيماران مبتلا به سندروم روده تحريكيذير بود.

\section{مواد و روشها}

يزوهش حاضر يك مطالعه آزمايشى با كارآزمايى بالينى است كه با

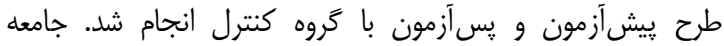

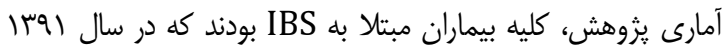
به مطب متخصصان گوارش شهر اردبيل مراجعه كرده بودند و

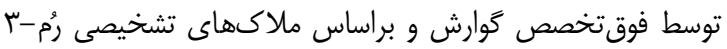
مبتلا به سندروم روده تحريكيذير تشخيص داده

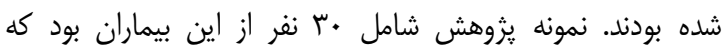
بلهورت دردسترس، انتخاب و سيس بهصورت تصادفى ساده در دو

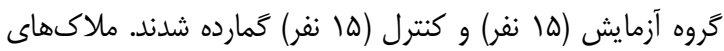
ورود به يزوهش شامل؛ ابتلا به سندروم روده تحريكيذير با

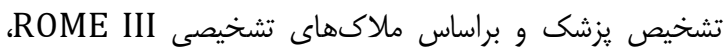

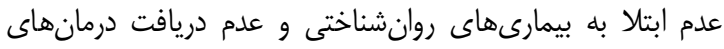

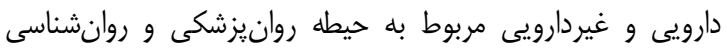

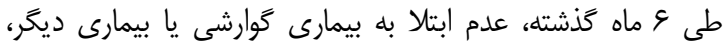

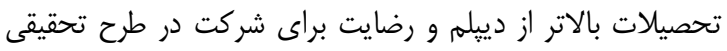

با رعايت نسبت بيماران مبتلا با غلبه اسهال يا يبوست يا مختلط و

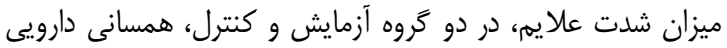

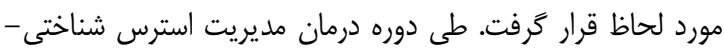

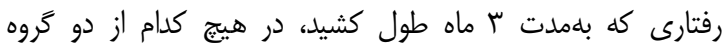
آزمايش و كنترل از طرف يزشك مربوطه تغييرى در نوع درمان دارويى و دوز دريافتى بيماران صورت نخرفت.

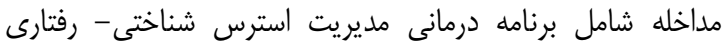

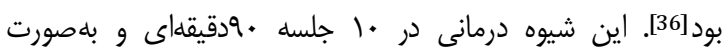
گروهى برَزار شد و فاصله زمانى جلسات يك بار در هفته بود

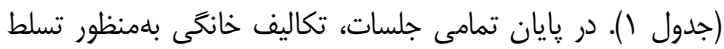

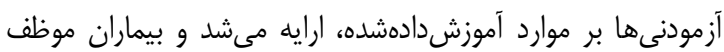

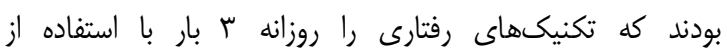

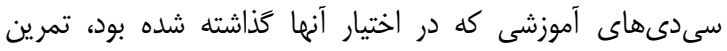
نمايند. ابزار يزوهش، يرسشنامه شدت علايم IBS براساس مقياس ROME III

$$
\text { رضايت از زندگى بود. }
$$

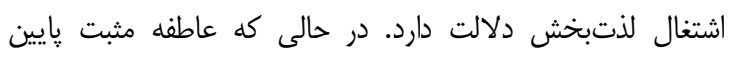
نشاندهنده غمخينى و رخوت است[17]. يزوهش حالي دها نشان دادهاند كه بين عاطفه مثبت و علايمم جسمانى رابطه منفى وجود دارد و عاطفه مثبت از طريق تقويت سيستم ايمنى باعث افزايش سلامت جسمى مئى

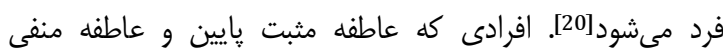
بالايى دارند، اغلب در طول روز، استرس بيشترى را تجربه مى كنند و در مقابل استرس حساستر هستند[21].

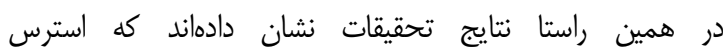

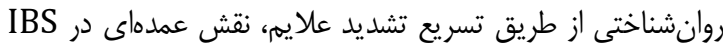

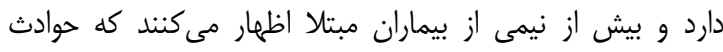

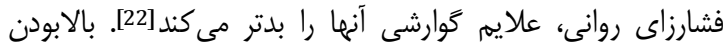
سطح استرس و افزايش شدت علايم منجر به كاهش كيفيت

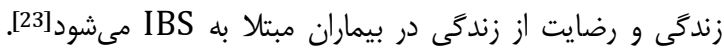

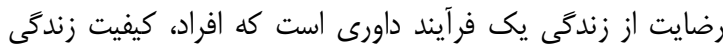
خود را براساس ملاكهاى منحصربهفرد خود ارزيابى مى كنند[24].

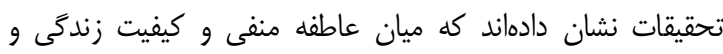
رضايت از زندگى در بيماران مبتلا به IBS رابطه منفى وجود دارد و بيمارانى كه عاطفه منفى بالاترى را تجربه مى كنند، كيفيت زندگى دئى مطلوبى ندارند[25].

درمانهاى مختلف دارويى و غيردارويى براى درمان بيماران مبتلا به IBS به كار گرفته شده است. از جمله درمانهاى دارويى ميىتوان به يروبيوتيكها، داروهاى مهاركنده بازجذب مجدد سروتهن (SSRIs)

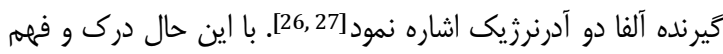
آسيبشناسى IBS در •r سال كذشته از يك ديدگًاه سادهانگارانه

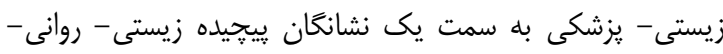

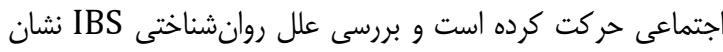
مىدهد كه درمانهاى روانشناختى مى توانند در كاهش نشانههاى بيمارى مفيد واقع شوند [28].

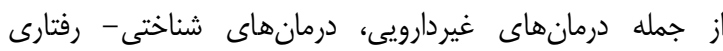

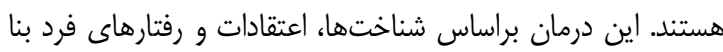

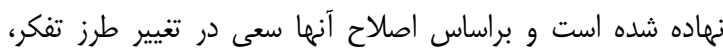

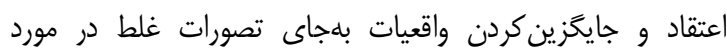
علايم جسمى و در نتيجه اصلاح عملكرد روانى و جسمى فرد دارد[29]. درمان مديريت استرس، بر رويكرد شناختى - رفتارى

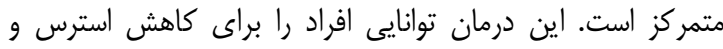

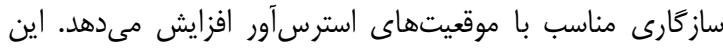

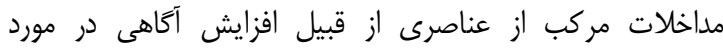

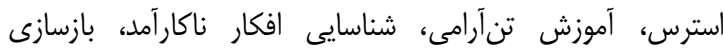

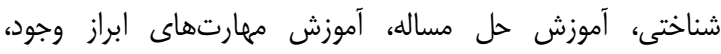

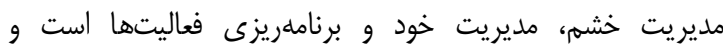
بdعنوان يك درمان روانشناختى در كاهش على علايم و بهبود وضعيت 


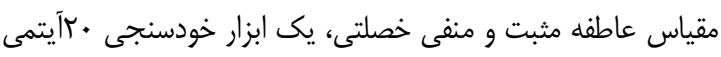

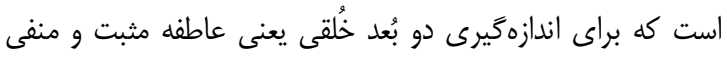

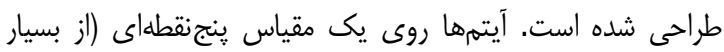

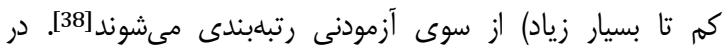

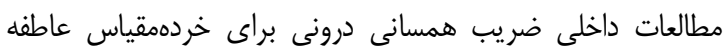

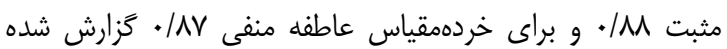

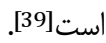

مقياس رضايت از زندكى داراى ها آيتم است كه براساس مقياس

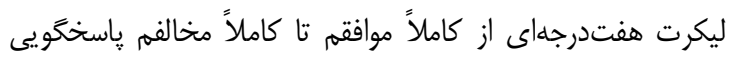

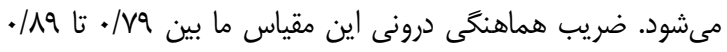

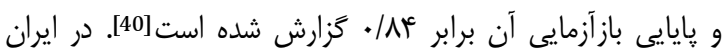

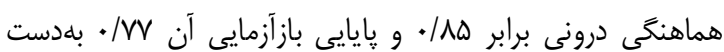

آمده است[24].

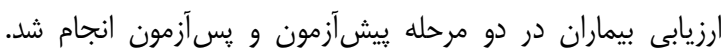

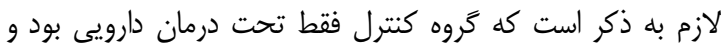

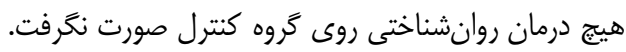

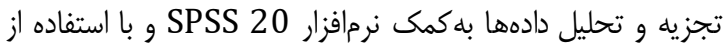

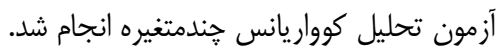

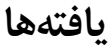

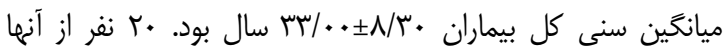

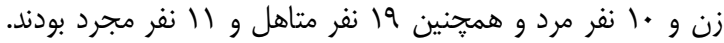

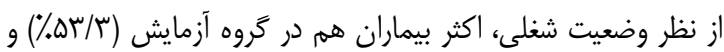

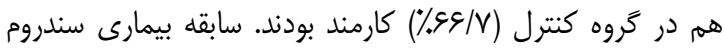

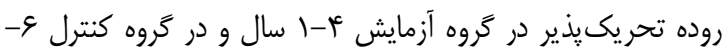

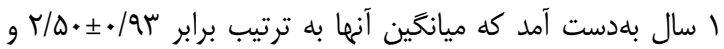

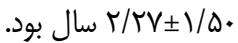

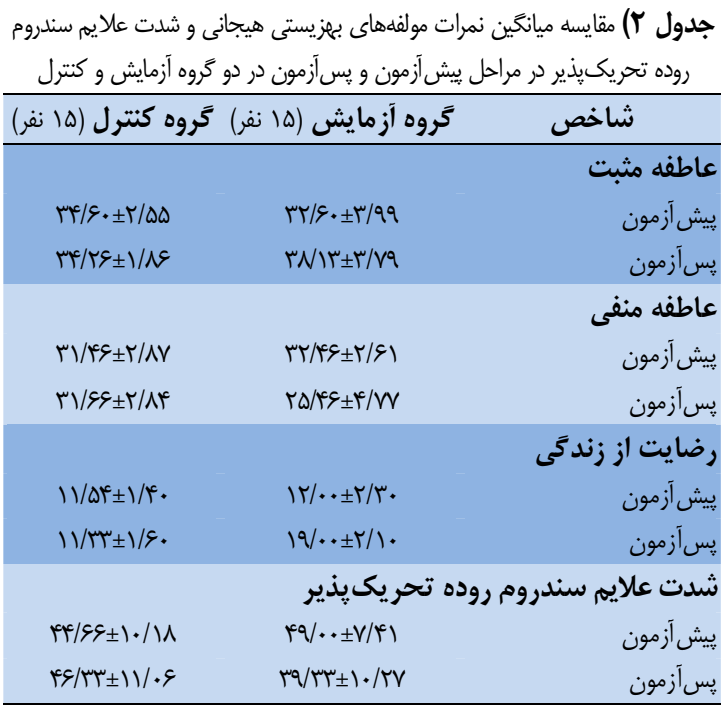

جدول () برنامه جلسات درمانى مديريت استرس شناختى - رفتارى

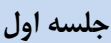

معارفه، بحث راجع به عوامل ايجادكننده استرس، نقش استرس بر شروع، تشديد

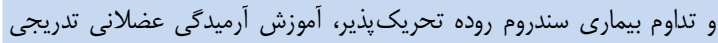

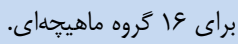

جلسه دوم

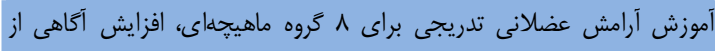
نشانههاى جسمى استرس.

جلسه سوم تصناك آموزش تنفس ديافراگمى، آموزش آرميدگى عضلانى تدريجى براى ثل كروه

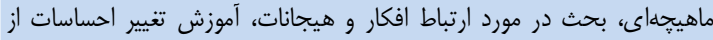
طريق تغيير طرز تفكر.

جلسه جههارم

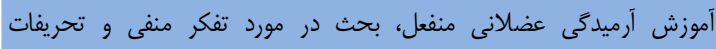

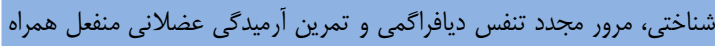

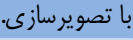
جلسه ينجم

آموزش خودزاد براى سنخينى و كرما، آموزش جايكزينى افكار منطقى بهجاى

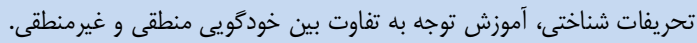

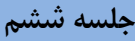

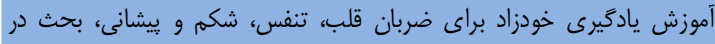

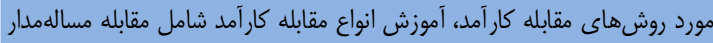
و و هيجانمدار. جلسه هفتم آموزش خودزاد همراه با تصويرسازى و خودالقايى و اجراى هاسخهاى مقابلهاى موثر. جلسه هشتم آموزش مراقبه و مانترا و مديريت خشمه، توضيح حالات بدنى حين مراقبه باقبه، بحث در مورد هاسخهاى خشم و ارايه گز ينههاى جايخزين. جلسه نهم آموزش مراقبه شمارش تنفس و آموزش خودابرازكرى، توضيح سبكهاى

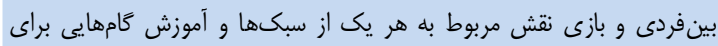

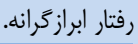

جلسه دهم تصويرسازى و مراقبه و بحث در مورد حمايت اجتماعى.

علاوه بر درنظركرفتن ملاكهاى تشخيصى ROME III،

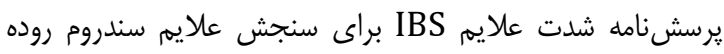

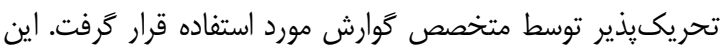

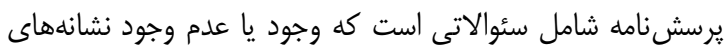

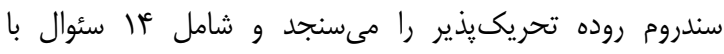

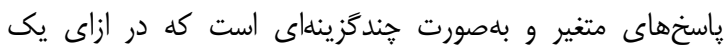

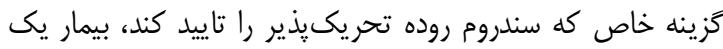

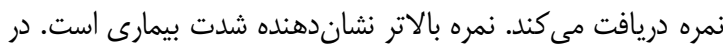

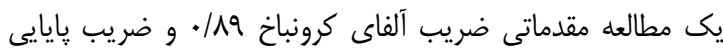
بازآزمايى (بعد از يك ماه) ه9 / • بهدست آمد [37]. 


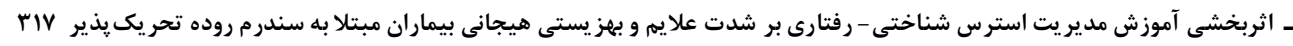

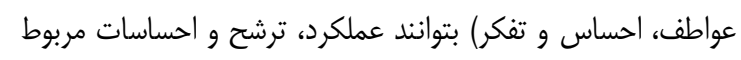

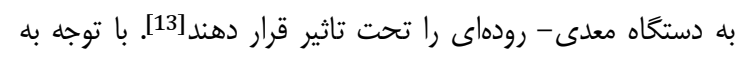

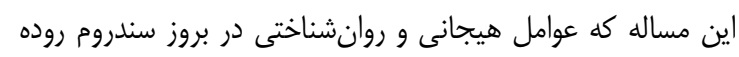

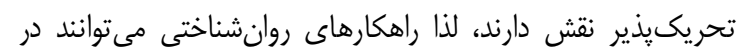
ييشخيرى و درمان اين بيمارى موثر باشند.

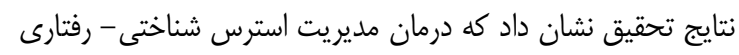
در كاهش شدت علايم و بهبود وضعيت هيجانى و ارتقاى رضايت

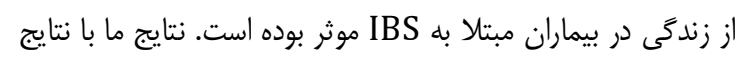

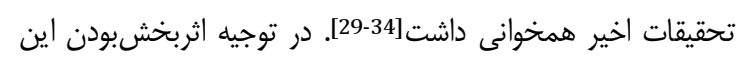

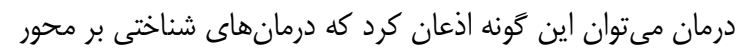

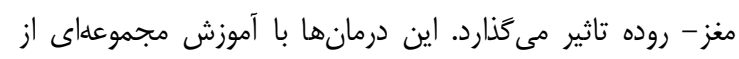

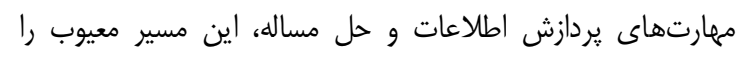

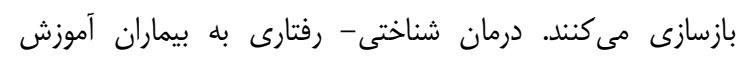

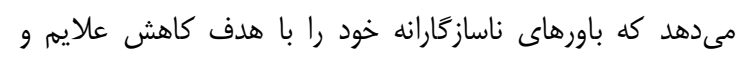

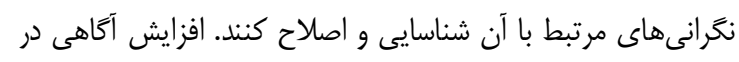

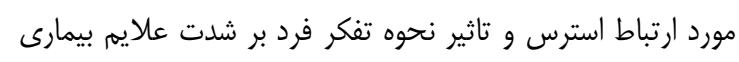

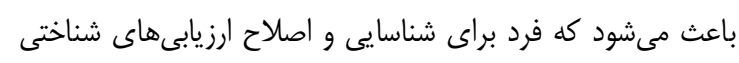

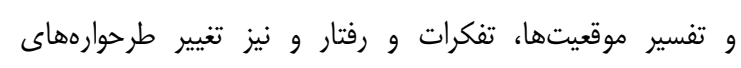
افزايشدهنده عاطفه منفى و افسردمى اقدام نمايد [13].

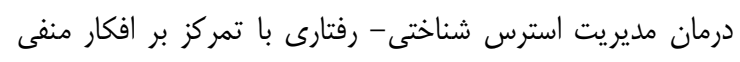

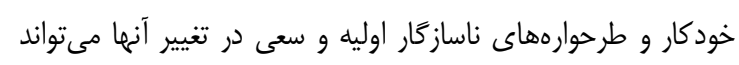

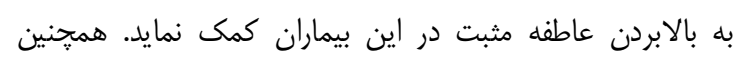

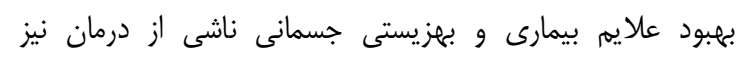

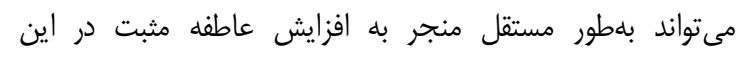

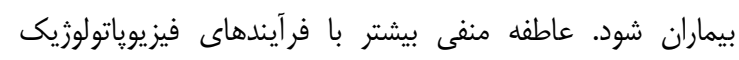

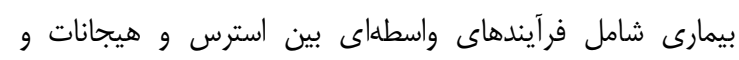

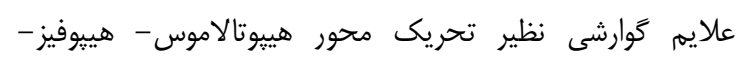

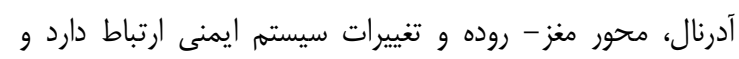

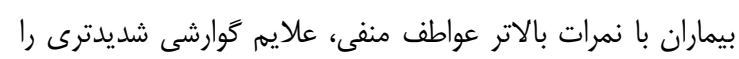

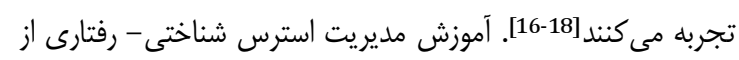

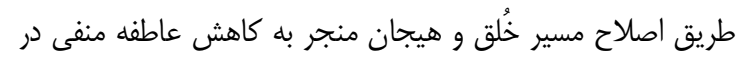

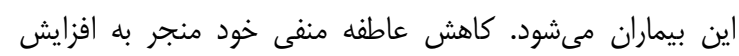

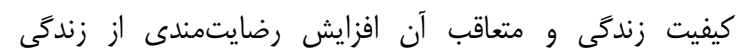
مى شود [25].

همجنين درمان مديريت استرس از جنبه رفتارى با ارايه تمر يناتى

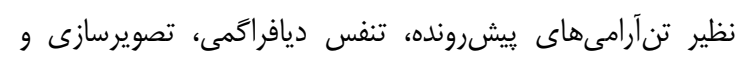

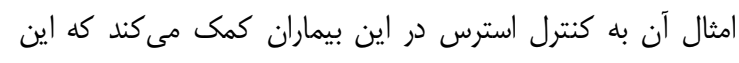

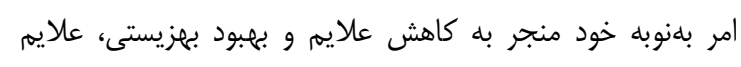

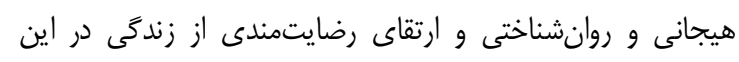
بيماران مىشود. يزوهش ما نظير همه يزوهشهارها داراى يك سرى محدوديتها بود.

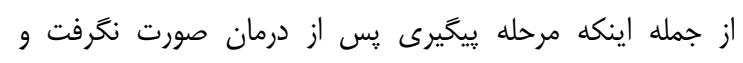

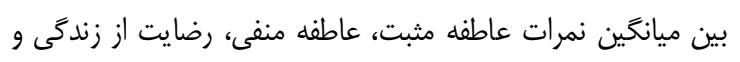

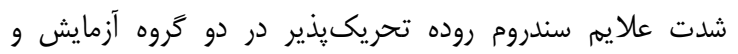

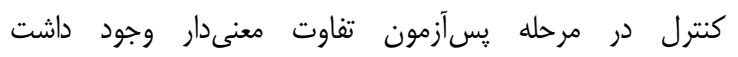

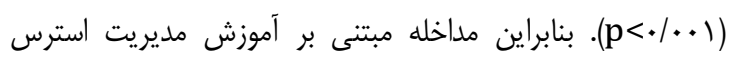

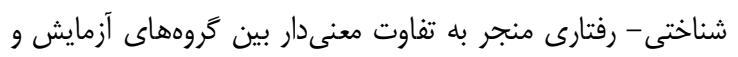

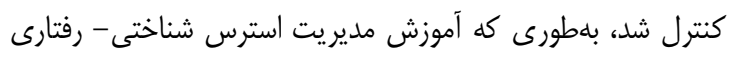

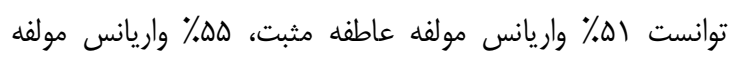

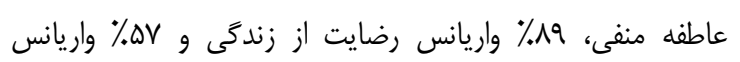

$$
\text { شدت علايم IBS را تعيين كند (جدول rاريانس رضايت آ زند). }
$$

بحث

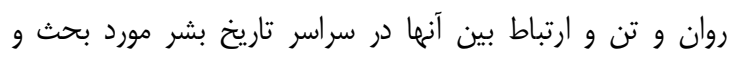

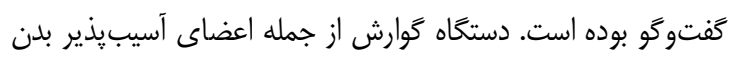

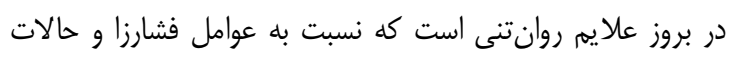

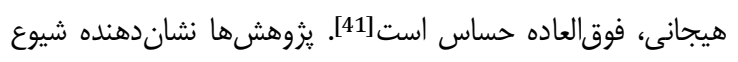

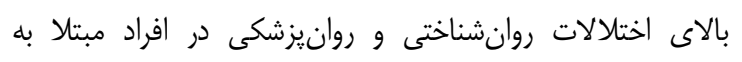

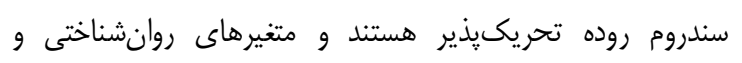

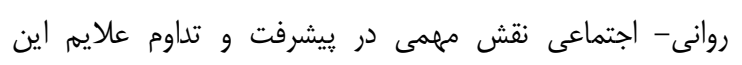

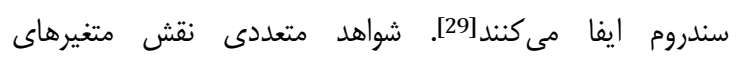

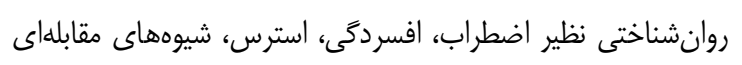

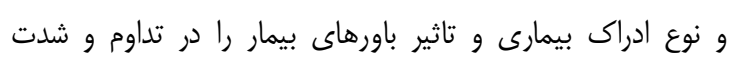
علايم IBS مورد تاييد قرار دادهاند [42].

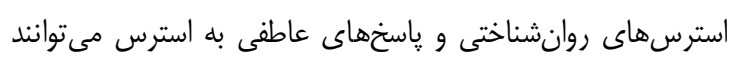

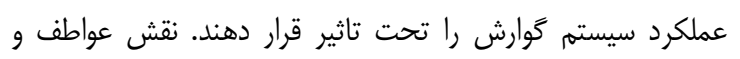

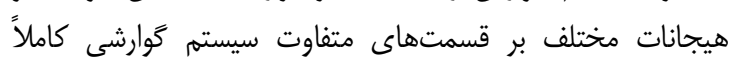

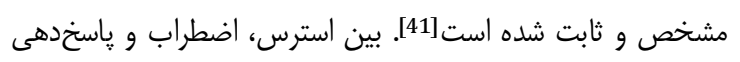

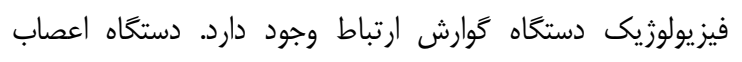

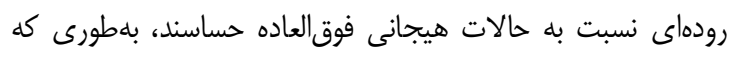

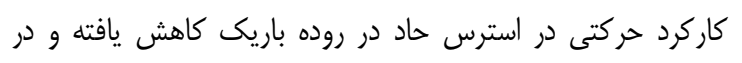

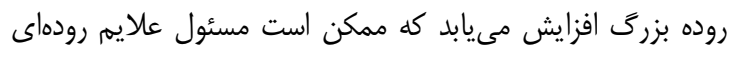

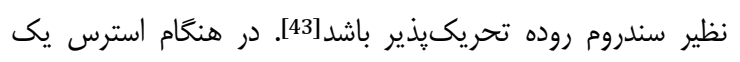

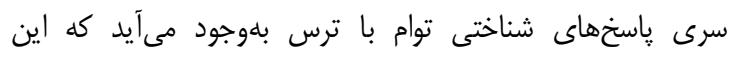

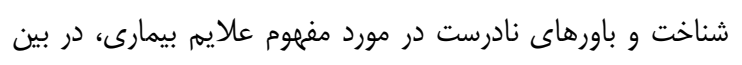

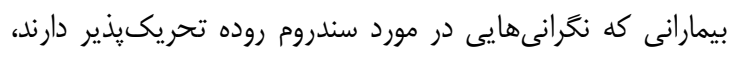
شايعتر است[44].

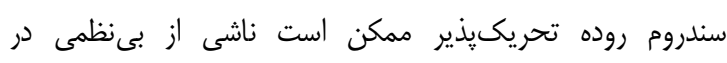

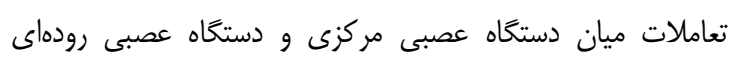

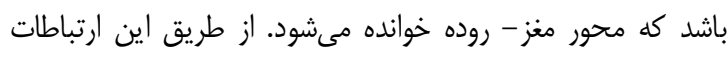

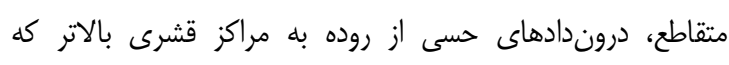

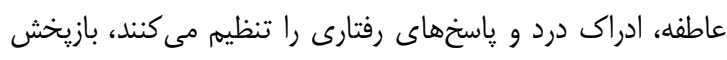

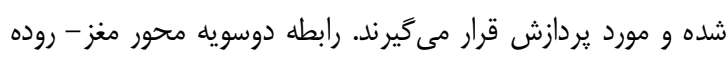

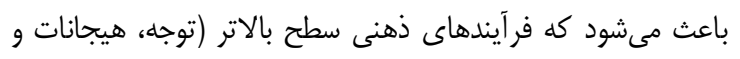


11- Madden JA, Hunter JO. A review of the role of the gut microflora in irritable bowel syndrome and the effect of probiotics. Br J Nutr. 2002;88:S67-72.

12- Dean BB, Aquilar D. Impairment in work productivity and health related quality of life in patient with IBS. Am J Manag. 2005;11(Suppl 1):17-26.

13- Patrick DL, Drossman DA, Frederick IO, DiCesare J, Puder KL. Quality of life in persons with irritable bowel syndrome: development of new measure. Dig Dis Sci. 1998;43(2):400-11.

14- Keyes CL. The mental health continuum: From languishing to flourishing in life. J Health Soc Behav. 2002;43(2):207-22.

15- Denollet J. Standard assessment of negative affectivity, social inhibition and type D personality. Psochosom Med. 2005;61(1):89-97.

16- Bagherian Sararoudi R, Kalantari H, Afshar $H$, Daghaghzadeh H, Abotalebiyan F, Falah J, et al. Relationship between negative affectivity and severity of irritable bowel syndrome symptoms. J Babol Univ Med Sci. 2012;14(2): 73-81. [Persian]

17- Muscatello MR, Bruno A, Scimeca G, Pandolfo G, Zoccali RA. Role of negative affect in pathophysiology and clinical expression of irritable bowel syndrome. Word J Gastroenterol. 2014;20(24):7570-860.

18- Bagherian Sararoodi R, Sanei H, Baghbanian A. The relationship between type $\mathrm{D}$ personality and perceived social support in myocardial infarction patients. J Res Med Sci. 2011;16(5):627-33.

19- Pellissier S, Dantzer C, Canini F, Mathieu N, Bonaz B. Psychological adjustment and autonomic disturbance in inflammatory bowel disease and irritable bowel syndrome. Psychoneuroendocrinol. 2010;35(5):653-62.

20- Dockray S, Steptoe A. Psitive affect and psychobiological processes. Neurosci Biobehav Rev. 2010;35(1):69-75.

21- Lex C, Bazner E, Meyer TD. Does stress play a significant role in bipolar disorder? a meta-analysis. J Affect Disord. 2016;208:298-308.

22- Whitehead WE, Crowell MD, Robinson JC, Heller BR, Schuster MM. Effect of stressful life events on bowel symptoms: subject with irritable bowel syndrome compared with subject without bowel dysfunction. Gut. 1992;33(6):825-30

23- Joc EB, Madro A, Celinski K, Slomka M, KasztelanSzczerbinask B, Pacian A, et al. Quality of life of patients with irritable bowel syndrome before and after education. Psychiatr Pol. 2015;49(4):821-33.

24- Sheikhi M, Hooman HA, Ahadi H, Sepah Mansoor M. Psychometric properties of satisfaction with life scale. Andishe va Raftar. 2011;5(19):17-29. [Persian]

25- Samadi Nazari M, Ebrahimi Daryani N, Yaraghchi A, Farrokhi N, Rezaei O. Predicting quality of life on the basis of type D Personality in patients with irritable bowel syndrome. Govaresh. 2013;18(2):80-7. [Persian]

26- Cash BD. Emerging role of probiotics and antimicrobials in management of irritable bowel syndrome. Curr Med Res Opin. 2014; 30(7): 1405-15.

27- Trinkley KE, Nahata MC. Treatment of irritable bowel syndrome. J Clin Pharm Ther. 2011;36(3):275-82.

28- Zomorodi S, Rasoulzadeh Tabatabaei SK, Arbabi M, Ebrahimi Daryani N, Azad Fallah P. Comparison of the effectiveness of cognitive - behavior therapy and mindfulness based therapy on the decrease in symptoms of patients who suffer from irritable bowel syndrome. Govaresh. 2013;18(2):88-94. [Persian]

$$
\begin{aligned}
& \text { محقق، خود بلعنوان درمانكر بود و اين مىتواند اثر هالهاى ران ران }
\end{aligned}
$$

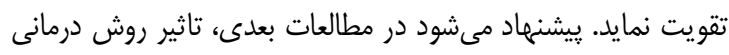

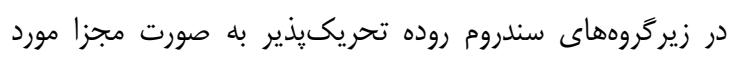

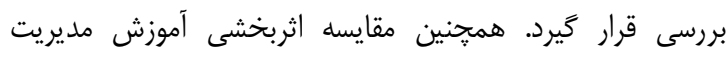

$$
\begin{aligned}
& \text { استرس با ساير درمانهاى روانشناختى مىتواند مفيد واقع شود. }
\end{aligned}
$$

$$
\begin{aligned}
& \text { نتيجه كيرى } \\
& \text { درمان مديريت استرس شناختى - رفتارى مىتواند در كاهش شدت }
\end{aligned}
$$

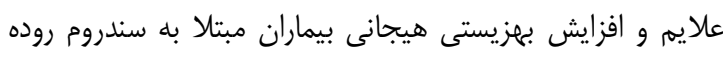

$$
\begin{aligned}
& \text { تحريكيذير موثر باشد. }
\end{aligned}
$$

تشكر و قدردانى: از تمامى بيماران عزيز كه در اين يثوهش شركت كردند، صميمانه تشكر مى كنيم.

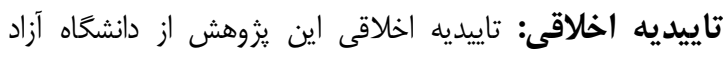

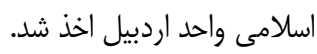

تعارض منافع: هيج گَنه موردى توسط نويسندكان گزارش نشده

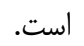

منابع مالى: اين مقاله حاصل ڤايان نامه دانشجويى مقطع كارشناسىارشد روانشناسى بالينى است.

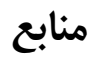

1- Drossman DA. Introduction: The Rome Foundation and Rome III. Neurogastroenterol Motil. 2007;19(10):783-6.

2- Canavan C, West J, Card T. Review article: The economic impact of irritable bowel syndrome. Aliment Pharmacol Ther. 2014;40(9):1023-34

3- Lea R, Whorwell PJ. Quality of life in irritable bowel syndrome. Pharmacoeconomics. 2001;19(6):643-53.

4- Canavan C, West J, Card T. The epidemiology of irritable bowel syndrome. Clin Epidemiol. 2014;6:71-80.

5- Jahanghiri P, Hashemi Jazi M, Hasannzadeh Keshteli A, Sadeghpour S, Amini E, Adibi P. Irritable bowel syndrome in Iran: Sepahan systematic review. Int J Pres Med. 2012;3(1):S1-9.

6- Hassanzadeh Keshtli A, Dehestani B, Daghaghzadeh H, Adibi P. Epidemiology features of irritable bowel syndrome and its subtypes among Iranian adults. Ann Gastroenterol. 2015;28(2):253-8.

7- Meleine M, Matricon J. Gender-related differences in irritable bowel syndrome: Potential mechanisme of sex hormones. World J Gasstroenterol. 2014;20(22):672543.

8- El-salhy M. Resent developments in the pathophysiology of irritable bowel syndrome. World J Gastroenterol. 2015;21(25):7621-36.

9- Tillisck K, Labus JS. Advances in imaging the brain-gut axis: Functional gastrointestinal disorders. Gastroenterol. 2011;140(2):407-11.

10 - Weston AP, Biddle WL, Bhatia PS, Miner PB. Terminal ileal mucosal mast cells in irritable bowel syndrome. Dig Dis Sci. 1993;38(9):1590-5. 
اثربخشى آموزش مدير يت استرس شناختى - رفتارى بر شدت علايم و بهز يستى هيجانى بيماران مبتلا به سندرم روده تحر يك يذير 19 19

Culver JL, et al. Cognitive -behavioral stress management intervention decreases the prevalence of depression and enhances benefit finding among women under for earlystage breast cancer. Health Psychol. 2001;20(1):20-32.

37- Abolghasemi A, Soleymani P, Rahimi A, Vakili Abasaliloo, S. Efficacy of stress management training on symptom severity and psychological wellbeing of patient with irritable bowel syndrome. Govaresh. 2014;20(3):178-84. [Persian]

38- Watson D, Clark L, Tallegen A. Development and validation of brief measures of positive and negative affect. The PANAS scales. J Person Soc Psycho. 1988;54(6):1063-70.

39- Bakhshipour A, Dezhkam M. Confirmatory factor analysis of the positive affect and negative affect scales. J Psychol. 2006;9(4):65-78. [Persian]

40- Diner E, Emmons RA, Larson RJ, Griffin S. The satisfaction of life scale. J Person Assess. 1985;49(1):71-5. 41- Tanum L, Malt UF. Personality and physical symptoms in non psychiatric patients with functional gastrointestinal disorders. J Psychosom Res. 2001:50(3):139-46.

42- Afshar H, Bagherian R, Foroozandeh N, Khorramian $\mathrm{N}$, Daghaghzadeh H, Maracy MR, et al. The relationship between illness perception and symptom severity in patients with irritable bowel syndrome. J Isfahan Med Sch. 2011;29(137):526-36. [Persian]

43- Mayer E. The neurobiology of stress and gastrointestinal disease. Gut. 2000;47(6):861-69.

44- Gomborone J, Dewsnap P, Libby G, Farthing M. Abnormal illness attitudes in patient with irritable bowel syndrome. J Psychosom Res. 1995;39(2):227-30.
29- Lackner JM, Jaccard J, Krasner SS, Kats LA, Gudleski CD, Holroyd, K. Self-administered cognitive behavioral therapy for modrate to sever IBS: Clinical efficacy, tolerability, feasibility. Clin Gastroenterol Hepatol. 2008;6(8):899-906.

30- Mahvi-Shirazi M, Fathi-Ashttiyani A, RasoolzadeTabatabaee SK, Amini M. Irritable bowel syndrome treatment: Cognitive behavioral therapy versus medical treatment. Arch Med Sci. 2012;8(1):123-9.

31- Reme SE, Kennedy T, jones R, Darnley S, Chalder T. Perdictors of treatment outcome after cognitive behavioral therapy and antispasmodic in primary care. J Psychosom Res. 2010;68(4):385-8.

32- Chilcot J, Moss-Morris R. Changes in illness-related cognition rather than distress mediate improvements in irritable bowel syndrome (IBS) symptoms and disability following a brief cognitive behavioral therapy intervention. Behav Res Ther. 2013;51(10):690-5.

33- Kamkar A, Golzary M, Farrokhi NA, Aghaee M. The effectiveness of cognitive - behavioral stress management on symptoms of patients with Irritable bowel syndrome. Armaghan-e-Danesh. 2011;16(4):30010. [Persian]

34- Tang QL, Lin GY, Zhang MQ. Cognitive-behavioral therapy for the management of irritable bowel syndrome. World J Gastroenterol. 2013;19(46):8605-10. 35- Ljotsson B, Folks L, Vesterlund AW, Hedman E, Lindfors $\mathrm{L}$, Ruck $\mathrm{CH}$, et al. Internet-delivered exposure and mindfulness based therapy for irritable bowel syndrome--a randomized controlled trial. Behav Res and Ther. 2010;48(6):531-9.

36- Antoni MH, Lehman JM, Kilbourn KM, Boyers AE, 